Combustion Rates and Mechanisms of Pulverized Coals and Coal-Derived Fuels

D. R. Hardesty

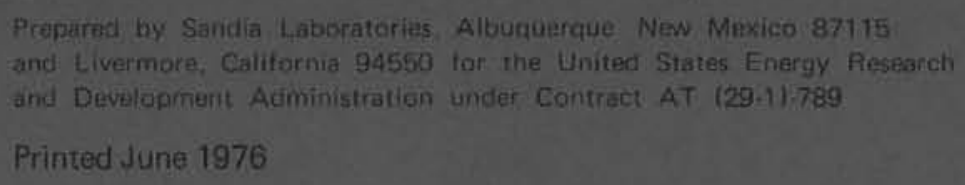

Sandia Laboratories energy report

When printing a copy of any digitized SAND Report, you are required to update the markings to current standards. 


\section{NOTICE}

This report was prepared as an account of work sponsored by the United States Government. Neither the United States nor the United States Energy Research and Development Administration, nor any of their employees, nor any of their contrac. tors, subcontractors, or their employees, makes any warranty. express or implied, or assumes any legal liability or responsibility for the accuracy, completeness or usefulness of any information, apparatus, product or process disclosed, or represents that its use would not infringe privately owned rights. 
SAND76- 8229

Unlimited Release

Printed June 1976

\title{
COMBUSTION RATES AND MECHANISMS OF \\ PULVERIZED COALS AND COAL-DERIVED FUELS
}

\author{
D. R. Hardesty \\ Combustion Research Division 8115 \\ Sandia Laboratories, Livermore
}

\begin{abstract}
Increased use of coal, our most abundant fossil fuel resource, will be required to meet both immediate and long-term energy demands. Although development and demonstration of new coal conversion systems and advanced coal combustors for fluidized beds, MHD and gas turbine systems combustors is underway, these new systems will have only minor impact on power generation capacity during the next 20 years. In contrast, improvement in existing technologies of steam raising and industrial process heating through the clean, direct firing of pulverized coal will have major and immediate impact. Improvements in these technologies are required because of the unacceptably high emissions from present coal combustion systems and because of the need to couple considerations of pollutant emissions and carbon conversion efficiencies.

It is well known that the rates and mechanisms of coal devolatilization and combustion are extremely sensitive to local details of the combustion process. Similarly, pollutants formed during the process are sensitive to the initial coal composition and local time and temperature histories of individual particles. Very little useful information is available by which the influence of combustion modifications on both the efficiency and pollutant emission characteristics can be predicted.

This report summarizes the present understanding of the rates of coal and char combustion. The present feeling is that heterogeneous chemical kinetic rates strongly influence the rates and mechanisms of coal and char combustion. If understood, adjustment and control of the rates and mechanisms by judicious adjustment of the combustion process and the initial fuel character should be possible. A proposal for a detailed theoretical and experimental study of the combustion rates of pulverized coal and coal-derived fuels is discussed.
\end{abstract}




\section{IN TRODUCT I ON}

The combustion of coal provides over $50 \%$ of the electrical power and over $25 \%$ of industrial process heat generated in the United States. At present rates of utilization, domestic supplies of natural gas and oil will be rapidly depleted. While it may be reasonable to postulate the effectiveness of energy conservation measures to reduce near-term demands and the development and expansion of new technologies (e.g., solar, fuel cell and fusion generators) to meet demands in the future, it is apparent that increased use of coal, our most abundant fossil fuel resource, will be required to meet both immediate and long-term demands. Pressure to rapidly expand the use of pulverized coal and coalderived liquid and gaseous fuels in direct-fired boilers and advanced systems such as large gas turbines and MHD topping cycles are expected to be accentuated by the increasingly uncertain future of nuclear fission power in this country.

Development or demonstration work is underway on numerous coal conversion systems and advanced schemes such as fluidized bed combustors. These new systems will, however, have only minor impact on power generation during the next 20 years. In contrast, improvement in existing technologies of steam raising and industrial process heating through direct firing of pulverized coal is expected to have major and immediate impact. Incorporation of these improvements in advanced systems will facilitate their optimization. It is the purpose of this discussion to elaborate on one of many areas, namely the characterization of the combustion properties of pulverized coal and coal-derived fuels, where improved understanding will contribute to improved technology. 
It has been argued ${ }^{1}$ that pulverized coal combustion is a well-established technology and that utilization aspects are largely environmentally oriented. From the exclusive standpoints of present generation combustor reliability, safety of operation, and conversion efficiency of carbon and hydrogen to $\mathrm{CO}_{2}$ and water vapor, the argument is sound. Satisfactory systems in the context of earlier economic and societal demands were engineered through trial-and-error development with little need for recourse to the understanding of the particular details of the combustion processes involved. There is now, however, increased concern for predicting and restricting combustion-generated pollutant emissions while simultaneously maintaining or improving (through advanced systems) thermodynamic efficiencies in coal combustors. The requirement to meet these objectives with coals of lower rank, higher ash and moisture contents and more widely variable properties magnifies the problem.

In Figure 1, the EPA regulations for pollutant emissions from new utility power plants are compared to estimates of uncontrolled emissions as a function of the fuel type consumed. In Figure 2 the required emission reductions according to these Federal requirements are summarized. Rules promulgated by individual states are in accord but in some cases are more stringent (for example, in California ${ }^{3}$ ). than the EPA standards and prohibit new large power sources from emitting pollutants which contribute to deterioration of local air quality. With pressure for increased coal utilization, it can be expected that present emission standards will be tightened and extended to include, for example, hydrogen sulfide, ammonia, hydrogen chloride and partially oxidized gas phase hydrocarbons including polycyclic aromatic compounds.

A review of published documents on the subject does not suggest that economic and rèliable technologies for meeting even the more modest standards are well developed, particularly for the case of coal-fired systems. At this date, given the poorly 
Figure 1. Summary of EPA Regulations for New Power Plants (Reference 2)

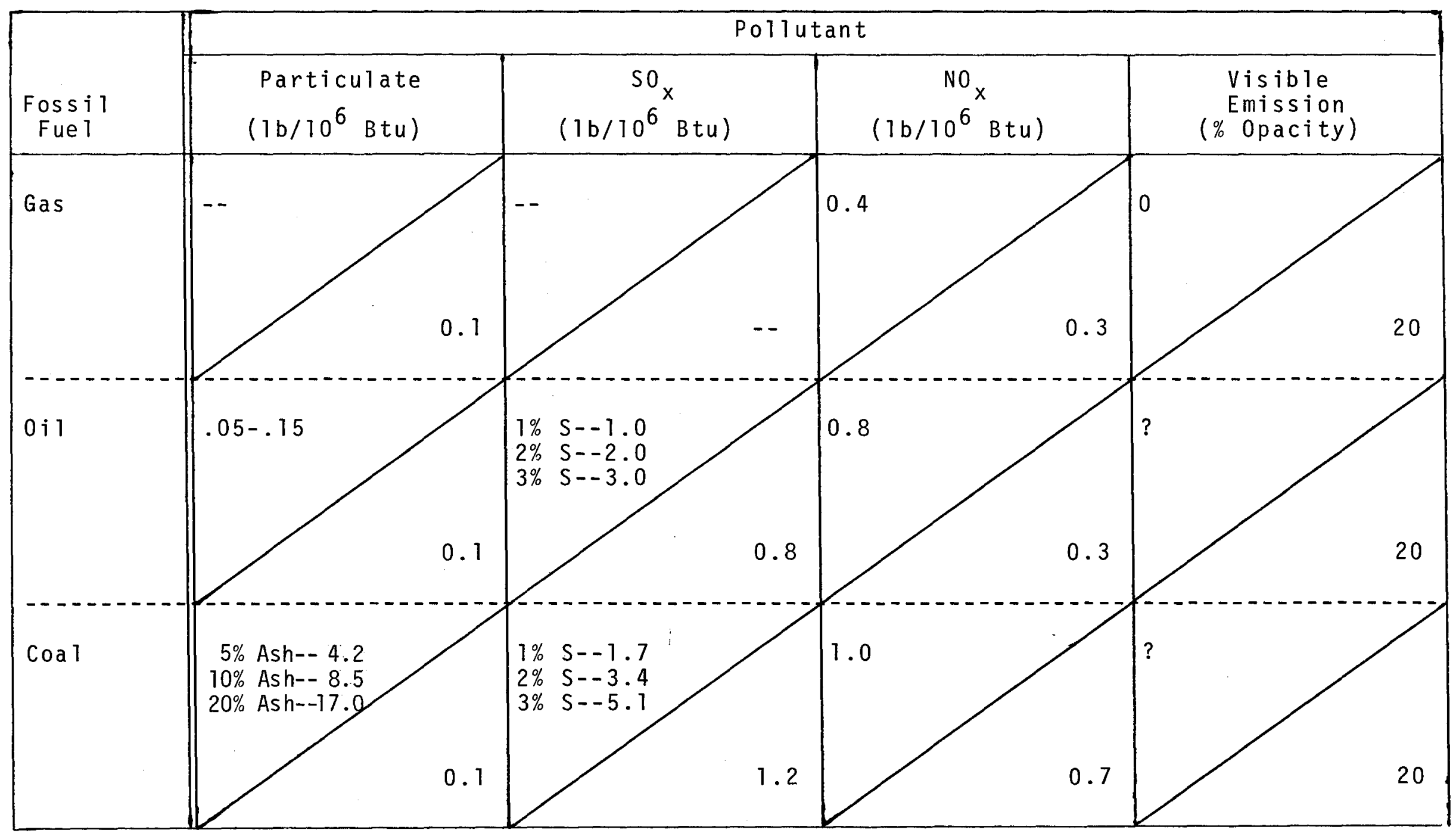

Key:

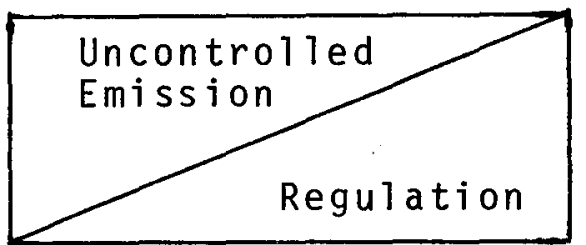


Figure 2. Required Emission Reduction (\%) According to EPA Regulations for New Power Plants (Reference 2)

\begin{tabular}{|c|c|c|c|c|}
\hline \multirow[b]{2}{*}{ Fue 1} & \multicolumn{4}{|c|}{ Pollutant } \\
\hline & Particulate & $\mathrm{SO}_{\mathrm{x}}$ & ${ }^{N} 0{ }_{x}$ & $\begin{array}{l}\text { Visible } \\
\text { Emissions }\end{array}$ \\
\hline Gas & None & None & 50 & None \\
\hline $0 i 1$ & $0-33$ & $\begin{array}{ll}0.8 \% & S-- \text { None } \\
1.0 \% & S--20 \\
2.0 \% & S--60 \\
3.0 \% & S--73\end{array}$ & 65 & 90 \\
\hline Coal & $\begin{array}{r}5 \% \\
10 \% \text { Ash }-97.6 \\
10 \% \text { Ash- }-98.2 \\
20 \% \text { Ash-- } 99.5\end{array}$ & $\begin{array}{ll}0.7 \% & S-- \text { None } \\
1.0 \% & S--30 \\
2.0 \% & S--65 \\
3.0 \% & S--80\end{array}$ & 30 & 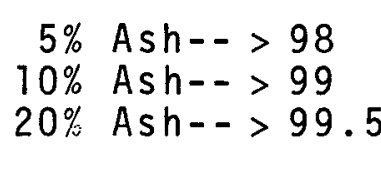 \\
\hline
\end{tabular}


understood nature of the combustion of pulverized coal and the well-tuned nature of existing plant operations, industry has been reluctant to invest capital in combustor modifications. As a consequence, efforts have concentrated on testing and monitoring of existing and new equipment, R\&D on exhaust gas monitoring and cleanup, fuel characterization and modification (through blending, use of additives and pulverization techniques) and easily and inexpensively implemented minor alterations in firing practices (e.g., the use of "over-fire air" to reduce ${ }^{N 0}{ }_{x}$ emissions ${ }^{4-7}$ ). often such modifications are contradictory to good combustion practice where high temperatures are required for heat transfer and complete combustion." 9 In many areas new plant construction has been virtually halted due to the lack of adequate, economic and reliable technologies for controlling emissions from coal-fired systems while maintaining high carbon conversion efficiency.

The need to couple considerations of emissions and efficiencies in coal combustors is true also for gas-and oil-fired combustors used for stationary and mobile power generation. Recognition of this need is in large measure responsible for increased concern for understanding the details of combustion processes in both a fundamental and an applied sense. ${ }^{0,01}$ As indicated schematically in Figure 3 , the present capacity to predict the characteristics of combustion processes and devices is inversely related to the sensitivity of those characteristics to the details of the combustion process. For the specific case of pulverized coal combustion, our ability to predict (and hence to design for) the simultaneous influence on burning rates and all pollutant emissions of changes in coal properties, degree of pulverization, fuel/air flow rates (loading) and mixture ratio, temperature, pressure, mixing patterns, turbulence and heat transfer is virtually nonexistent. At best, minor extrapolations can be made on existing systems, based on trial-and-error testing. 


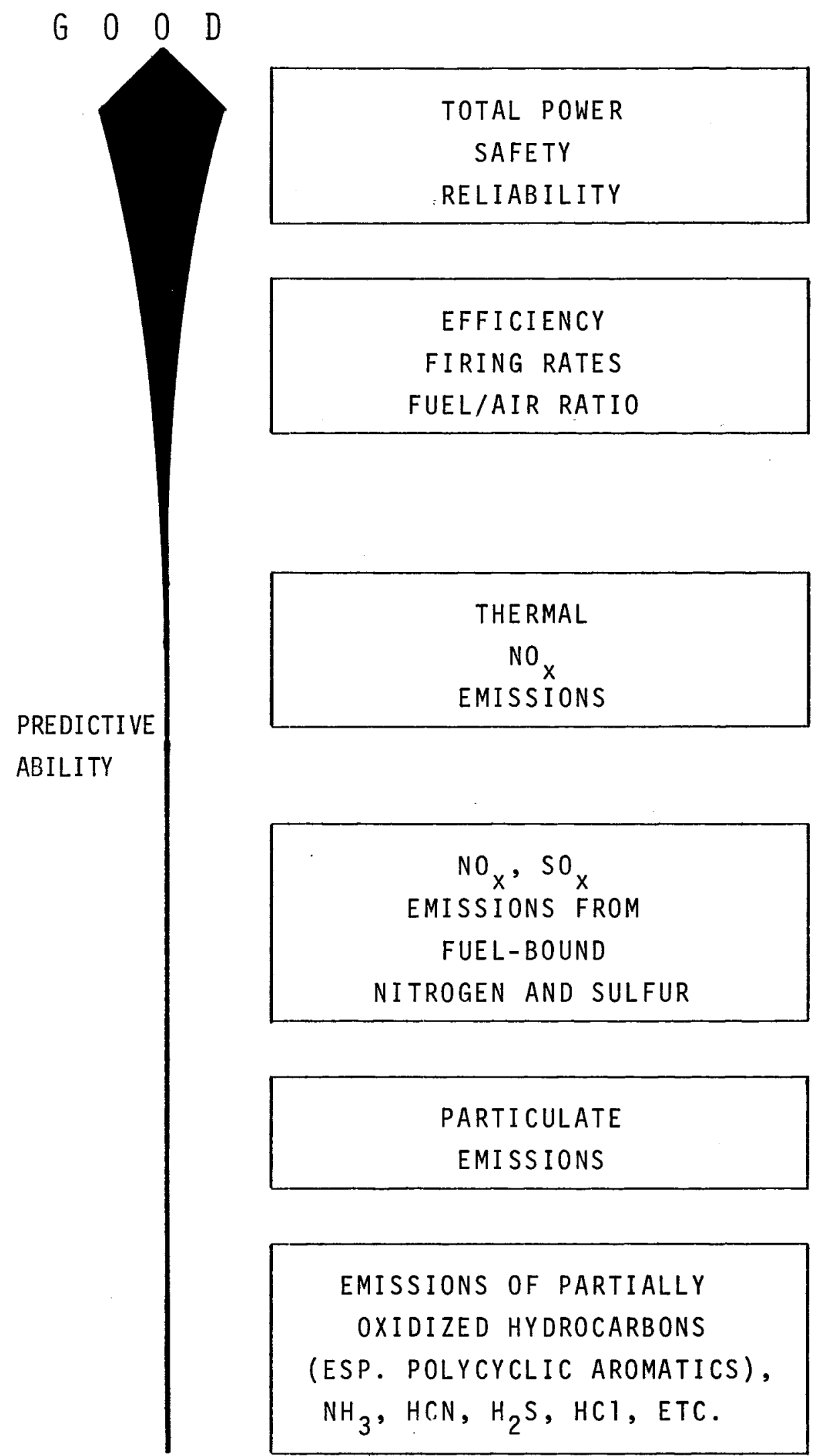

W E A K

SENSITIVITY

TO DETAILED

COMBUSTION

PROCESSES

AND FUEL

CHARACTERISTICS

$P \quad 0 \quad R$

$S T R O N G$

Figure 3. Schematic Comparison of Our Ability to Predict Combustor Characteristics and the Sensitivity of These Characteristics to Fuel Type and Details of the Combustion Process 
Heywood 2 has emphasized the importance of combustion details by observing that small empirical modifications in the combustion process and fuel composition in conventional engines have produced significant changes in emission characteristics without compromise in efficiency. Similarly, emissions and performance of utility boilers have shown response to major empirical changes in firing practice and to redesign of individual burners. ${ }^{13}$ As indicated in Figures 1 and 2, coal-fired systems have the largest emissions in pounds per unit of heat input and require the largest emissionsreductions. It is also widely recognized that coal-fired systems are the most difficult to control as well as being the most sensitive to changes in operating conditions and fuel characteristics.8.9 These problems may be aggravated by increased burning of low-sulfur, sub-bituminous Western coals. Due to their high moisture content (only part of which can be driven off by conventional drying techniques), these coals have very low heating values. In order to meet a constant steam generation requirement, a substantial increase of coal/airloading may be required. Since nitrogen content is relatively independent of coal rank, a substantial increase in $\mathrm{NO}_{\mathrm{x}}$ emissions per $10^{6}$ Btu is possible.

While empirical modification of firing practices will remain as an important means for improvement of conventional systems, it seems logical to suggest that a coordinated, parallel effort of basic and applied research on the combustion characteristics of coal, chars and coal-derived liquid fuels will yield much useful information. While the technical information on the mechanisms of combustion of pulverized coal in conventional boilers is limited, there is even less information which is relevant to direct coal-firing of proposed pressurized advanced systems such as fluidized beds and gas turbines and very high-temperature systems such as MHD combustoris. The research program proposed here will have impact upon each of these systems and will furnish information required for their optimization. Despite the importance of the problem to the nation and to ERDA and despite recent pleas $8,17,48$ for increased $R \& D$ efforts, this is a severely under-funded area. 
COMMENTS ON THE MECHANISMS OF COMBUSTION OF PULVERIZED COALS

Previous Investigations

There exists an extensive literature on the physical and chemical properties of carbon, coal, char, coke and coal extracts. A similarly extensive history of the mechanisms of decomposition, oxidation and combustion of 1 arge and pulverized samples of these materials is also to be found. Much of the work prior to 1963 is summarized by van Krevelen ${ }^{14}$ and Lowry. ${ }^{15}$ Since 1963, a great deal of data and conjecture have accumulated on the mechanisms of pyrolysis and combustion of pulverized coals and chars. No attempt will be made here to review these works. A partial tabulation is listed in the References. In particular, the reviews by Lowry, ${ }^{15}$ Field, et al.,$^{16}$ Mulcahy and Smith, ${ }^{7}$ and Gray, Cogoli and Essenhigh ${ }^{18}$ are recommended for their discussions of data relating to basic mechanisms of pulverized coal and char combustion and for their interpretations of these data according to simple heuristic models. Practical aspects of the combustion of pulverized coals and chars in experimental systems which simulate utility boiler conditions are reviewed by Lowry ${ }^{15}$ and Field. ${ }^{16}$ Summaries of research prior to 1969 on the combustion of pulverized coal in fluidized beds ${ }^{19}$ and direct-fired coal combustors for MHD ${ }^{20}$ are also of interest.

The principal objectives of virtually all of these studies have been to provide quantitative information in response to certain practical questions, viz, can the process efficiency or 
yield (in the case of coal conversion systems) be increased? And, can reduction in combustor size and hence capital costs be made? To answer these questions, attention has been focused at determining absolute rates of pyrolysis and combustion of pulverized coals and chars.

The principal independent variables in these studies can be grouped as they relate to the properties of the unreacted coal or char, to the experimental apparatus employed and to the conditions within each experiment. These variables include:

- Properties of the unreacted coal or char

- -Rank (anthracite $\rightarrow$ bituminous $\rightarrow$ sub-bituminous $\rightarrow$ lignite)

--Proximate analysis (percent by weight of moisture, volatiles, fixed carbon, ash, according to a standardized ASTM test)

--Particle size or size distribution

--Porosity, swelling characteristics, density and specific heat

- - Heat of combustion

NOTE: With the exception of particle size and size distribution, these variables are inter-related in a complex fashion for each material examined.

- Experimental system used

- Laminar flow reactors (Ref. 16 and 21-31)

--Turbulent, plug flow reactors (Ref. 16, 32, 33)

--Laminar coal-dust flames (Ref. 34, 35)

--Shock tubes (Ref. 36-38)

--Crucibles or suspensions of single sample or particles (Ref. 14, 16, 39)

--Simulated furnaces (Ref. 9, 15, 16, $19-21,41,42$ ) 
- Experimental conditions

- Total pressure

- - oxygen partial pressure

--0xygen/fuel total mixture ratio

--Fuel, oxygen, diluent flow rates

--Presence of additives

- Gas temperature

- Particle or sample heating rate

--Quench rate of partially reacted sample

NOTE: Depending upon the experimental apparatus, not all of these variables were controlled

independently in each study.

A variety of relatively straightforward diagnostic techniques have been applied. Samples of unreacted material were analyzed and, in most cases, compared to samples of partially reacted gases and solids which were extracted after various durations in a heated reactor vessel. Samples have been chemically analyzed, subjected to ASTM volatility and porosity tests and examined by light microscopy and scanning electron microscopy. Sampling rates were typically much slower than required for local quenching of the gas or solid sample. In part, this has been due to the inability to prevent plugging of small sampling tube passages by large or agglomerated particles. Only very recently have rapid quench isokinetic ${ }^{4}$ and molecular beam ${ }^{3}$ sampling systems been applied to examine product gas compositions in laminar pulverized coal flames. Many of the experiments have been designed to study reaction at fixed gas temperature or fixed particle heating rate. Uncoated thermocouples have been used to measure gas temperatures (which are generally reported as uncorrected for conduction and radiation losses), with pressure taps or pitot tubes for pressure measurement. Particle temperatures have been assumed equal to gas temperatures or estimated from two-color or suction pyrometer measurements. There are several examples of the use of light absorption to measure temperature, but no account was taken 
of single or multiple scattering effects. In a few cases, visual and cinematographic information was obtained. In the shock tube work, broadband emission centered about $800 \mathrm{~nm}$ was sensed by a photodiode and used to estimate ignition times.

In the following section, a brief summary is given of the principal results of these experimental studies. It will be noted that although there is some consistency among the data of individual investigations and even some agreement on absolute magnitudes of overall rates obtained in different experimental systems, there remains much controversy over interpretations of the data in terms of mechanisms. As Mulcahy ${ }^{17}$ and Essenhigh ${ }^{18}$ have emphasized, much of the data can be shown to be suspect and ambiguous. Consequently, in each case stated conclusions must be weighed carefully in order to sift among results which in many cases may be artifacts of the experimental system and conditions. Interpretations are still largely in the realm of personal judgment rather than established scientific fact. ${ }^{43}$ As regards the influence of the solid material properties, the composition temperature, pressure and turbulence level of the gas phase and the particle heating rate on the mechanisms of pyrolysis and combustion, the definitive experiments remain to be done. With the exception of the inference that part of the No which is formed is due to fixation of atmospheric nitrogen, there is virtually no direct evidence on the physical and chemical mechanisms of pollutant formation from the combustion of pulverized coals and chars.

As we indicated earlier, questions of safety, economy, reliability and efficiency of new boilers are now intimately related to consideration of pollutant emission reduction. The feasibility and optimization of advanced high-temperature systems such as the direct-fired turbine and MHD combustors will depend in part upon precise control of both rates of combustion and rates of pollutant formation. 
Principal Results and Interpretations of Previous Work

Extensive data on the pyrolysis of coals and chars at low temperature $\left(<1000^{\circ} \mathrm{K}\right)$ and very low heating rates (< $1^{\circ} \mathrm{K} / \mathrm{sec}$ ) in inert and oxidizing atmospheres is reported by van Krevelen. ${ }^{14}$ These data cannot be extrapolated to conditions relevant for combustion in utility boilers, gas turbines and MHD combustors where peak temperatures from $1500^{\circ} \mathrm{K}$ to $2700^{\circ} \mathrm{K}$ and heating rates of $10^{4}$ to $10^{5} \mathrm{o} / \mathrm{sec}$ are realized. Similarly, data obtained for large samples in the relevant temperature and pressure range are also of questionable use.

These observations follow from a consideration of the complex physical arid chemical structure of coal and from the interaction of that structure with the combustion environment as a function of the heating rate. In Figure 4, a model due to Given ${ }^{46}$ of the C-H-N-O structure of a coal molecule is shown. In Figure 5 , Hirsch's mode $1^{47}$ of the physical microstructure of coal, considered as an organic rock, is shown.

Based on these and similar models, the following points are crucial to the interpretation of all previous experimental data on coal pyrolysis and combustion.

- In comparison to saturated, aliphatic hydrocarbons (e.g., $\left.\mathrm{CH}_{4} \ldots \mathrm{C}_{8} \mathrm{H}_{18}\right)$, coal has a low ratio of hydrogen to carbon atoms $(H / C)$ as a consequence of its high aromaticity (condensed "benzoid" ring structure)

- The coal molecules have a high degree of polymerization and are arranged in more or less ordered fashion in layers (Hirsch's lamellae), depending upon the coal rank. Lower rank coals (e.g., Western lignites) have a much more open structure than the higher rank coals (Eastern bituminous and anthracites). The polycyclic molecular layers are linked by intermediate $-C-C-$ and $-C-0-C-$ bonds. Molecular weights from 2000 to (essentially) infinite are estimated. 


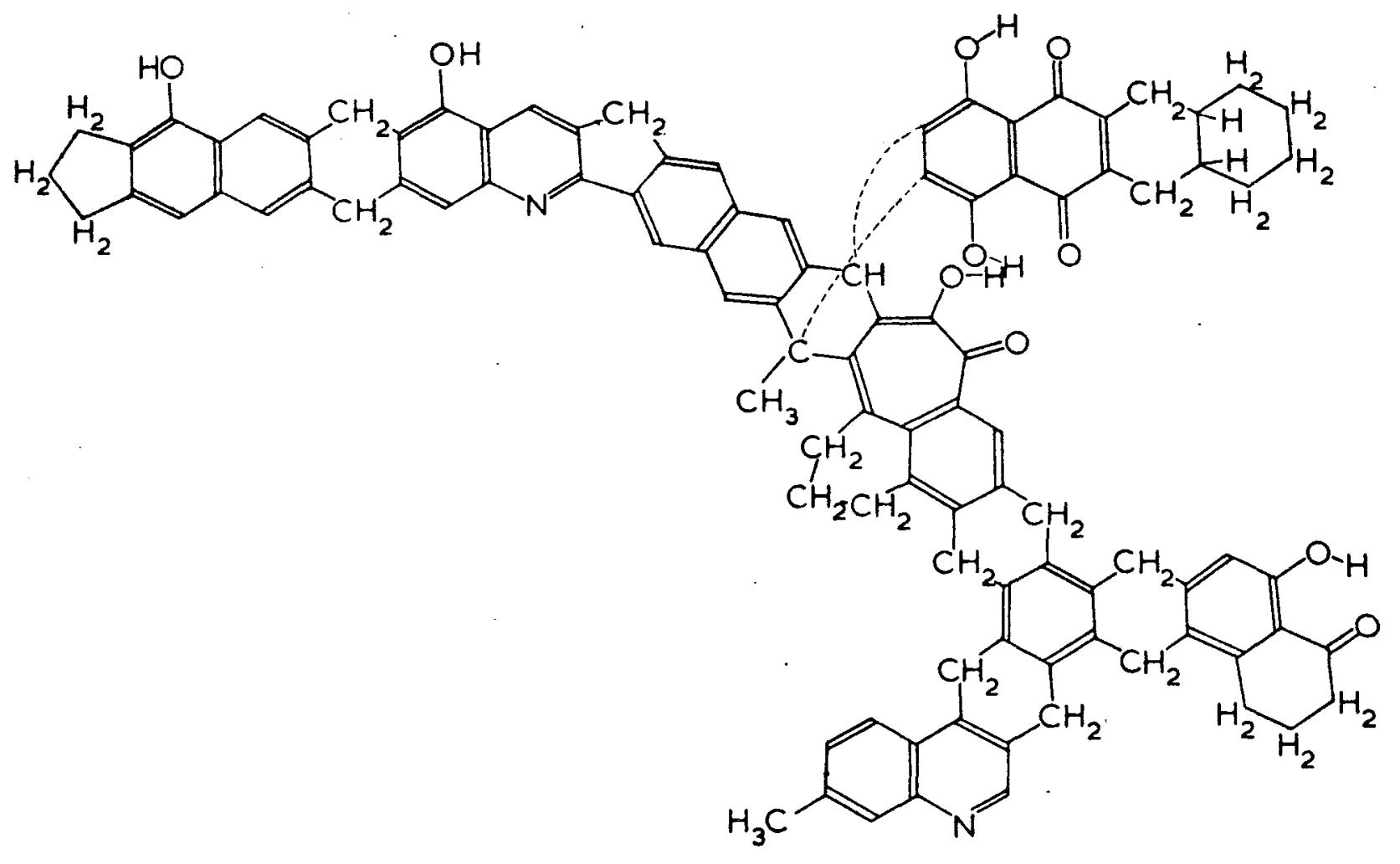

Figure 4. Model Due to Given ${ }^{46}$ of Structure of Coal Molecule

NOTE: Fuel-bound nitrogen and sulfur (not shown) occur mainly in relatively stable heterocyclic rings within the molecule. Most of the oxygen is contained in reactive functional groups on the periphery of the molecule. Carbon and hydrogen occur in both the aromatic and aliphatic (open-chain) groups. 


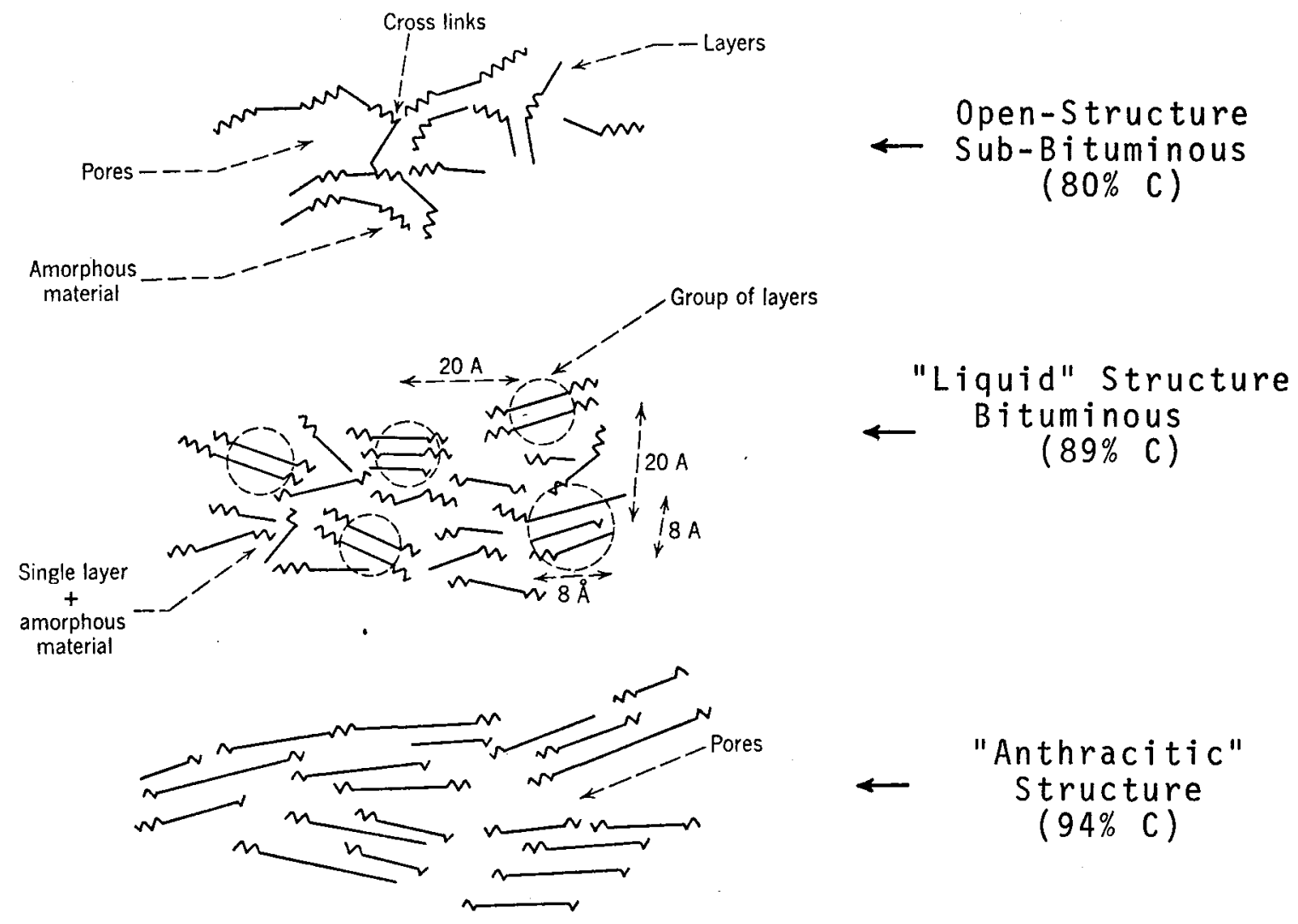

Figure 5. Schematic Model of Coal Microstructure According to Hirsch ${ }^{47}$ 
- As an organic rock, coal has a variable density whigh increases with rank from approximately 1 to $2 \mathrm{gm} / \mathrm{cm}^{3}$. The low density is a consequence of the highly porous nature of coal. In fact, most coals have a bimodel pore structure which greatly increases the surface area of a single particle. Internal surface areas in the range of 10-200 meters $2 /$ gram have been measured. This corresponds to a maximum of about $1 \mathrm{~cm}^{2}$ of total area for a $100 \mathrm{\mu m}$ particle having a density of $1 \mathrm{~g} / \mathrm{cm}^{3}$. The high porosity is partly responsible for the swelling and reactivity characteristics of coals (e.g., particles of lower rank, more porous coals are typically "more reactive" and may undergo greater changes in size upon heating than higher rank coals (swelling very strongly depends upon heating rate).

- According to Hirsch's model (Figure 5), the porosity is a consequence of the ordering and extent of cross linking of the aromatic layers.

- The aromatic C-C II bonds within each molecule and layer are much stronger than the aliphatic $-\mathrm{C}-\mathrm{H}_{2}$ bonds within the molecule, and the nonaromatic cross-link bonds between layers.

- In the course of crushing, cleaning (to remove ash and pyrites), drying and pulverizing coal, prior to firing, significant changes in pore structure can occur. It is found, for example, that porosity increases with finer grinding due to additional fracturing. However, pulverizing to very fine sizes can actually lead to sealing of macro pores with a consequent decrease in reactivity. In most practical systems, coal is pulverized to sizes $\lesssim 100 \mu \mathrm{m}$ (90\% by weight less than $200 \mathrm{mesh} .(75 \mu \mathrm{m})$ is a typical size requirement for a large furnace).

In light of these properties, it is generally accepted that studies of the pyrolysis (endothermic decomposition upon heating in the absence of oxygen) and oxidation of coals at low temperatures and low heating rates have relevance only to conditions which might arise in a poorly designed combustor where inadequate mixing or flame instabilities produce excessively rich zones. Under such conditions, sufficient time is available for the relatively slow depolymerization reactions (bond scission at the aliphatic and cross-link bridges) to occur with the formation of high molecular weight 1 iquid and gaseous tars and non-aromatic 
species. These materials may then undergo further slow gas phase cracking reactions to form lower molecular weight species or may recondense within the coal pore structure, possibly with the formation of even more energetic cross-link bonds. Such processes dominate in the absence of convection and rapid heating and in the pressure of large samples of solid material (e.g., in crucibles and in the ASTM volatile-matter test or in very rich stagnant zones in a combustor).

On the other hand, for small particles at high temperatures, the pyrolysis and oxidation processes are radically different. Under these conditions, based on the experimental studies noted above, the following inferences have been drawn:

The combustion of pulverized coal particles occurs in two, usually distinguishable stages. The first stage involves a rapid devolatilization of the particle and occurs in times on the order of 10-200 msec (longer times for lower heating rates and temperatures, 1 arger particles, and higher rank coals). The second stage involves the heterogeneous combustion of the devolatilized residual solid material--the char. The overall rate-limiting step in coal combustion is this second stage which requires times of 0.5 to 5 seconds depending upon the material properties and combustion environment. Since the principal concern of previous studies has been to gather sufficient data to allow quantitative prediction of total combustion times for sized particles as a function of the experimental conditions, many of the investigations have used coal chars as the initial fuel material. In addition to supplying information on overall rates, the data have been interpreted in terms of the influence of diffusion and chemical kinetics on the observed rates. In the cases where kinetics has been deemed controlling, reaction mechanisms have been proposed. The influence of the coal and char particle size, porosity and composition and the particular experimental conditions, especially the oxygen partial pressure and the temperature, on the observed rates and mechanisms have been examined.

Devolatilization

- The devolatilization stage is preceded by an induction or ignition delay time which is dependent upon heating rate. During this interval, the coal particle is rapidly heated to temperatures in excess of $1000^{\circ} \mathrm{K}$. In most cases, 
gas and particle temperatures have been equated; however, there is some evidence that particle superheating to temperatures $500^{\circ} \mathrm{K}$ to $700^{\circ} \mathrm{K}$ higher than the gas temperature may occur. Either case represents much higher initial temperatures than used in earlier studies. Under these conditions, ignition occurs on or very close to the particle surface and is nearly coincident with volatile evolution.

The decomposition mechanisms, devolatilization rates and total weight of material evolved are apparently strong functions of particle size, temperatures and heating rates. During rapid devolatilization at higher temperatures and higher heating rates, larger fractions of lower molecular weight species (e.g., $\mathrm{H}_{2}, \mathrm{CO}, \mathrm{CO}_{2}, \mathrm{H}_{2} \mathrm{O}$, gaseous $\mathrm{HC}$ ) in addition to tars are evolved. With reference to Figures 4 and 5 , it is suggested that these species derive from rupture of the $-\mathrm{H}_{2},-\mathrm{CH},-\mathrm{CH}_{2},-\mathrm{CH}_{3}$ and $-\mathrm{OH}$ bonds which appear on the periphery of the coal molecule as well as a more complete disruption of the weaker cross-link bonds between layers, followed by rapid removal of these species from the particle and their subsequent fast gas phase oxidation in lieu of condensation and repolymerization on the particle. During this stage, approximately $20 \%$ of the fuel-bound nitrogen is evolved probably in the form of reactive $\mathrm{CN}$, $\mathrm{NH}$ and $\mathrm{NH}_{2}$ radicals and $\mathrm{NH}_{3}, \mathrm{HCN}$ and $\mathrm{NO}$ species.

- It has been suggested that devolatilization is kinetically 1 imited for particles less than $100 \mu \mathrm{m}$. Hence, heterogeneous surface reaction is presumed to dominate with rapid diffusion of the evolved species away from the particle. For larger particles, diffusion becomes more important and may lead to larger, less porous char particles due to inhibited loss of volatilized material from within the particles.

- Various interpretations have been made of measured devolatilization rates in terms of rate-limiting heterogeneous surface reaction mechanisms. Since few timeresolved measurements (e.g., of species mass fractions and solid residue composition) have been made, these interpretations remain dubious at best. Conflicting reaction orders and rate constant parameters have been suggested. The influence of porosity on the available surface area for reaction is poorly understood. The chemical mechanisms and their response to details of the combustion environment remain essentially a mystery.

Combustion of the Devolatilized Char Residue

As noted above, due to the practice of pulverizing coals to sizes less than $100 \mu \mathrm{m}$, the principal component of the overall combustion time in a practical system is the time 
required to burn the involatile residue, the char, following devolatilization. This time is a strong function of the char properties, and hence of the original coal

properties, and the preceding time and temperature $h$ istory of the devolatilization process. The conventional wisdom is that while the rate of char combustion depends on the local combustion environment, it also depends strongly on the initial conditions which are just those obtained after rapid devolatilization.

- Char combustion rates are reported by Field, et a1.16,21,22 Badzoich and Hawksley, Anson, et al. ${ }^{24}$ Baum and Street ${ }^{2}$ and Smith, et al.26-3i Mulcahy and Smithi have compared observed rates from various investigations and discussed these in terms of the interaction of various possible rate-controlling mechanisms.

- Due to the disruption of the original organic structure and loss of the more reactive species during devolatilization, chars are much less reactive than the parent coal. However, as might be expected, they are even more porous (especially more of the large pores) than the original coal. The existence of this open-pore structure is generally believed to have a strong influence on the mechanisms and rates of char combustion. Chars derived from lower rank coals are observed to be "more easily combusted"--i.e., to burn more rapidly--than chars obtained from high rank coals.

- It is agreed that char combustion involves both surface and gas phase oxidation processes with mass diffusion and chemical kinetics playing important roles. The relative importance of these processes is a matter of some debate.

For large char particles ( $>100 \mu \mathrm{m}$ diameter) at temperatures above $1200^{\circ} \mathrm{K}$, Mulcahy and Smith ${ }^{17}$ have shown that all of the data obtained prior to 1969 are consistent with the assumption that mass transfer by diffusion of oxygen to the particle surface is the slowest step and, hence, ratelimiting; that a fast heterogeneous reaction of overall stoichiometry $\mathrm{C}_{s}+\frac{1}{2} \mathrm{O}_{2} \rightarrow \mathrm{CO}$ occurs at the surface; and that $\mathrm{CO}$ oxidizes to $\mathrm{CO}_{2}$ in the gas phase close to the particle. Under these conditions, the surface reaction of each molecule of $\mathrm{O}_{2}$ yields two molecules of gaseous products and, hence, the maximum rate of carbon consumption is predicted. For this simple model (which fits the data), the rate of combustion is equal to the rate of diffusion of oxygen to the exterior surface of the char particle (porosity is neglected) and reaction occurs on the exterior surface at constant particle density and decreasing particle size. The predicted rate, $R_{d i f f}$, is obtained 7 as :

$$
R_{\text {diff }} \sim\left[\left(D_{0} / d\right) \rho_{0}\left(T / T_{0}\right)^{0.75} \mathrm{ln} F\right],
$$


where $D_{0}$ is the average diffusion coefficient, $d$ is the diameter of the spherical particle, $T$ is the "reaction temperature," $\rho_{0}$ and $T_{0}$ are the reference gas density and temperature, and $F$ is a function of the oxygen mass fraction in the free stream. By this model, the oxygen concentration at the particle surface is negligible compared to the free stream concentration; and the combustion rate is independent of total system pressure ( $\left.D_{0} \sim 1 / p, \rho_{0} \sim p\right)$, weakly dependent on the temperature and inversely proportional to particle size. These conclusions for char particles larger than $100 \mu \mathrm{m}$ are independent of the parent coal rank.

Since $R$ diff $\sim 1 / d$, as the char particle size decreases, the rateif mass transfer increases. If it is presumed that chemical mechanisms do not also change, the influence of finite rate chemical kinetics becomes more important. Measured rates of char combustion for particles initially less than $100 \mu \mathrm{m}$ in diameter are, in some cases, several orders of magnitude lower than predicted by models based on simple diffusional control. It is, therefore, generally accepted that chemical kinetic control is important in char combustion at 1 atmosphere total pressure. ${ }^{17}$

- Given that the kinetics of the heterogeneous surface reactions are apparently important if not actually controlling for most char particles found in pulverized coal combustors, most investigations have attempted to distinguish the relative importance of various overall mechanisms. Early investigations assumed that reaction occurred on the exterior particle surface, even for smaller particles. There are indications that this is not what actually happens. Scanning electron micrography 44 of fly ash collected from coal-fired utility boiler exhausts indicate extensive formation of cenospheres. Similarly, samples of char, which have been examined after partial combustion, reveal higher porosity and some cenosphere formation with only small changes in outside particle diameter. Thus, the weight of new, admittedly rather scanty, data suggests that the internal pore structure of the char is actively involved in the burning process. For bituminous coal char particles, $40 \mu \mathrm{m}$ in size, it has been suggested ${ }^{17}$ that chemical kinetic mechanisms must be based on partial or total penetration of the pore structure by the oxidizing species. The degree of penetration is presumed to be a function of pore size. Because of the high ratio of internal to external surface area for a porous char, such arguments suggest that over a significant fraction of the total combustion time the particles may burn at nearly constant outside diameter but with decreasing density due to reaction on the pore surfaces. 
- Reaction mechanisms are uncertain. Gray, et al. ${ }^{18}$ and Mulcahy ${ }^{17}$ suggest that the combustion mechanisms for the smaller char particles can be described in terms of discrete processes for which overall rate constants and reaction orders can be estimated from experimental data. These processes include mass transfer by diffusion of the oxidizing species to the particle surface and diffusion of these species throughout the internal pore structure; chemisorption of the gaseous reactants onto the internal and external particle surface; desorp- tion of the gaseous reaction product from the surface; and mass transfer by diffusion of the product away from the particle surface. Reaction orders, activation energies and pre-exponential factors for these overall processes are uncertain. The wide scatter in reported values reflect uncertainty in the basic data, artifacts of the measurement technique or experimental apparatus and the different heuristic models applied to allow determination of overall kinetic constants. Clearly, assumptions about the activity of the internal pore structure and the particle temperature will significantly influence the interpretation of the data. In the case of rate control by chemical kinetics, increase in total pressure and particle temperature will increase burning rates. If the internal surface area is involved, then it may dominate the entire process. In that case, finer grinding to reduce the exterior particle diameter and increase the total number of particles will have little effect on the total rate of combustion. 


\section{STATEMENT OF PROPOSED WORK}

Virtually all previous studies of the pyrolysis and combustion of pulverized coal and char have emphasized a determination of overall rates of conversion to $\mathrm{CO}_{2}$ and $\mathrm{H}_{2} \mathrm{O}$. These studies have shown that finite rate chemical kinetics exerts an important influence on these rates for particles in the size range relevant to conventional and advanced pulverized-coal-fired systems. Interpretations of these data are based on heuristic models of likely overall processes. The relative importance of various mechanisms remains uncertain at best. Unanswered questions toward which further research proposed here is directed include:

1. What are the relative rates and mechanisms of formation of the major products, $\mathrm{CO}, \mathrm{CO}_{2}$ and $\mathrm{H}_{2} \mathrm{O}$, as a function of total pressure, local gas temperature and composition, particle temperature, and heating rate?

2. How do these processes relate to the rates and mechanisms of formation of undesirable gas phase pollutants such as $\mathrm{NO}, \mathrm{NH}_{3}, \mathrm{HCN}, \mathrm{SO}_{2}$, residual $\mathrm{CO}$ and unburned hydrocarbons ( $H C$ ), particularly polycyclic aromatic species?

3. What is the influence of $\mathrm{OH}$ radicals and, hence, of $\mathrm{H}_{2} \mathrm{O}$ content in the gas phase and absorbed within the particle, on relative rates of conversion to stable products and pollutants? In practical combustors, flame stabilization is strongly influenced by entrainment of hot combustion products. Hence, oxidation rates and mechanisms must be determined in the presence of $\mathrm{H}_{2} \mathrm{O}$ and $\mathrm{CO}_{2}$. Similarly, what is the influence of finite ${ }^{2} \mathrm{CO}_{2}$ concentrations in the oxidizing gas on rates and mechanisms?

4. What is the temperature of reacting particles? 
5. What is the influence of local turbulence levels and time scales on the combustion properties of particles less than $100 \mu m$ ? In this regard, Bagwe11, et al. 45 have estimated time scales on the order of 10-50 msec for turbulent eddies in a large utility boiler. These times are long compared to so-called devolatilization times and indicate rather $10 \mathrm{w}$ turbulent intensities. Since $100 \mathrm{\mu m}$ particles are calculated to follow stokes flow for mean stream velocities in the range pertinent to conventional boilers (in the higher temperature regions, particles up to several hundred microns will observe stokes flow), it is likely that they will also follow velocity fluctuations about the mean. It is likely, therefore, that most particles in the pulverized coal size regime (< $75 \mu \mathrm{m}$ ) are convected with the flow and, hence, burn (in a Lagrangian sense) in a quiescent environment, unaffected by turbulent fluctuations. This postulate needs to be investigated.

6. How do the properties of the parent coal and char, including particle size, particle size distribution, porosity, ash composition and rank influence observed rates and mechanisms?

A coordinated experimental and theoretical program is proposed. In addition to providing answers to specific basic questions, including those listed above, it is desirable to obtain overall data such as ignition and flammability limits and flame-spreading velocities in controlled sprays and suspensions of pulverized coal and char. Several experimental facilities will be modified or constructed to permit measurements of the combustion properties of single particles and suspensions or sprays of pulverized coals and chars. 
Theoretical

A complementary theoretical effort will be undertaken to permit correlation and interpretation of experimental data. Oneand two-dimensional solutions of the Navier-stokes equations for laminar and turbulent homogeneous reacting flows are presently being used at Sandia Labs to predict local velocities, concentrations and temperatures using detailed chemical kinetics. As a first step in treating a gas flow containing reactive coal or char particles, the conservation equations can be written assuming two discrete phases: a flow of gaseous material ( $\rho_{g} u_{g}$ per unit area) and a flow of solid particles ( $\rho_{s} u_{s}$ per unit area). In this formula.. tion $\rho_{g}$ and $u_{g}$ are the actual density and velocity of the gas phase, $u_{s}$ is the local velocity of the solid material and $\rho_{s}$ is the particulate loading density or the solid mass per unit gas volume. Two simplifications which should be entirely realistic for pulverized coal and char particles are neglect of the volume of the solid phase and assumption of no slip (Stokes flow) between the particles and the gas. The latter assumption can, of course, be tested. The influence of alternative rates of heat exchange among the gas, particles and boundaries and rates of diffusion and reaction between gas and particles will be examined using heuristic models based on previous work. These models will be updated as new information is provided from the experimental work. Of particular interest is an examination of the influence of rapid internal reaction within porous particles, particularly as this influences the particle temperatures. Conditions leading to particle superheating will be defined. 


\section{Experimental}

Useful answers to the important unresolved questions on the basic mechanisms and rates of coal and char combustion can only be provided by new local time- and space-resolved measurements in the vicinity of well characterized, sized particles undergoing reaction in known environments.

As a first step toward accomplishment of this objective, it is proposed to modify or duplicate an existing large-diameter laminar flame facility to permit the addition either upstream or downstream from the flame front, of small quantities of a defined distribution of coal and char particles. The time history of the combustion of these particles in the known, uniform, oxygen-rich post-flame gases will be followed using various experimental techniques. Simulation of radiant heating will be achieved by enclosing the flow field with a high-temperature ceramic tube (slotted for optical access) which will be heated by a concentric flame. Since residence time within the laminar flame front will be on the order of $1 \mathrm{msec}$, it is expected that addition of the particles upstream of the flame front will suffice.

Particle sizes in the range of relevance to practical combustors will be examined, i.e., less than $100 \mu \mathrm{m}$. Under the experimental conditions the particles will experience stokes flow. Residence time in the well-defined laminar flow of the flame product gases will be controlled by varying flow velocity. Particle heating rate will be adjusted by varying the temperature of the ceramic enclosure and by varying the temperature of the product gases. By virtue of burner cooling and oxygen enrichment, the composition and temperature of the flame product gas can be varied over wide ranges of relevance to existing and advanced systems. The use of oxygen-rich, wet $\mathrm{CO} / \mathrm{O}_{2} / \mathrm{N}_{2}$ and $\mathrm{H}_{2} / \mathrm{O}_{2} / \mathrm{N}_{2}$ flames will be used to examine independently the influence of variable $\mathrm{H}_{2} \mathrm{O}$ and $\mathrm{CO}_{2}$ concentrations on rates and mechanisms. Oxygen-rich $\mathrm{CH}_{4} / \mathrm{O}_{2} / \mathrm{N}_{2}$ flames will be used as a standard reference. 
Diagnostic measurements will include quenched samples of gas species and solid residue with analysis by a combined gas chromatograph/mass spectrometer system. For this purpose, novel designs of sampling probes will be examined. These will incorporate small applied electric fields for in situ separation of solids (which will be positively charged by thermionic emission in the hot product gases) and the gas species. Conventional water-cooled or uncooled quartz microprobes will also be applied.

In addition, for the dilute particle suspensions involved, it is anticipated that $C W$ and pulsed 3 aser Raman and fluorescence spectroscopy can be used to identify principal reaction products and major intermediates including radicals such as $\mathrm{OH}, \mathrm{CH}, \mathrm{CH}_{2}$, $\mathrm{CH}_{3}, \mathrm{CN}, \mathrm{NH}$ and $\mathrm{NH}_{2}$. A high intensity pulsed dye laser, tunable over ultraviolet wavelengths, will be employed to enhance signal/ noise ratio in the Raman and fluorescence measurements. An attempt will be made to use the fluorescence technique to identify gas phase nitrogen; sulfur and polycyclic aromatic molecules. Raman spectroscopy, sampling and thermodynamic equilibrium calculations will be used to characterize the hot product bath gases in the absence of coal and char particles. Two-color pyrometry will be used to measure particle temperatures.

Additional experimental facilities will be incorporated in the program.

- An existing shock tube will be used to obtain time- and spectrally-resolved information on the ignition and early devolatilization reactions of suspensions of pulverized coal in controlled oxidizing atmospheres. The shock tube facility will also be used for calibration of the Raman and fluorescence techniques. In these calibration studies, signals from species (e.g., oxygenated polycyclic aromatic compounds) which occur in coal combustion will be measured at high temperature in inert atmospheres. These data will be used for comparison with measurements made in the actual coal combustion experiments. ${ }^{2} 6$ 
- A high-pressure, constant volume combustion bomb will be used for subsequent measurements of the auto-ignition limits, minimum ignition energies and overall burning rates of suspensions and sprays of pulverized coals as a function of initial air temperature, pressure (up to 20 atm) and composition, and particle size distribution.

- The feasibility of carrying out similar studies at much higher total pressures and initial air temperatures in an adiabatic compression system will be examined.

In each of the proposed investigations, in-house analytical chemistry laboratories will be used for proximate and ultimate analyses of the unreacted coal and char and collected solid material. All studies will consider the influence of rank and ultimate analysis of the parent coal. The use of model aromatic compounds in some phases of the work will be considered. Where possible, high-speed cinematographic observation of the reacting material will be applied using existing equipment. 


\section{PROGRAM TASK AND SCHEDULE}

The proposed program is ambitious. The extent of the theoretical and experimental effort reflects the need to acquire a great deal of basic information which is presently unavailable. The proposed work will be coordinated with the study of $\mathrm{NO}_{x}$ formation from fuel-bound nitrogen. ${ }^{49}$

During the first year, heuristic models of the pyrolysis and combustion of coals and chars will be incorporated into existing laminar flow codes. These models will be improved as new information becomes available. Also during the first year, the required sampling equipment and sample analysis facilities will be designed or purchased as required. A major plant expense item in this regard will be the purchase of a combined gas chromatograph/mass spectrometer analys is system and associated data reduction/software systems. Assembly and calibration of the system will be completed during the first year. An integral part of this procedure will be the design and testing of novel probe designs to allow simultaneous isokinetic collection and separation of solid/gas samples. Optical spectroscopic techniques will be applied to determine the influence of finite sampling rates on local compositions and temperatures in laminar reacting flows. Modification or duplication of existing variable pressure laminar flame burners for use in the coal studies will be completed. Depending upon the coordination of the above tasks, actual diagnostic studies using the laminar flow facility will begin during the last quarter of the first year. 
During the second and third years, extensive studies of particulate-seeded flames as described in the Statement of Proposed Work section will be carried out. Quantitative assessments of results will be reported at frequent intervals. Also during the second year, shock tube studies will be initiated using existing facilities; and design and construction of the high-pressure combustion bomb will be completed. At this time, the feasibility of the high-pressure, high-temperature pulsed adiabatic compression device will be examined in light of information gained in the laminar flow and shock tube facilities.

Figure 6 shows the approximate time-scale of the major projects. 
Figure 6. Approximate Time-Scale of Major Projects

Project

Theoretical Code Development

Laminar Flow Code

Coal and char combustion model added

Turbulence effects added

Laminar Flow Reactor Study

Modify laminar flow sys tem for particulate addition

New sampling probe design, construction, evaluation using existing burners

Install and calibrate gas analysis system

Set up spectroscopic equipment for Raman and fluorescence studies and particle temp. measurement

Evaluation of pulsed dye laser system for $S / N$ reduction in luminous flame containing particulates

Probe sampling and spectroscopic studies of coal and char combustion

Analys is, evaluation, reporting of data

Shock Tube Studies

Modification of existing equipment for use of pulverized coal Two-color pyrometry calibration Study of ignition and devolatilization of suspensions of coal particles

study of effects of additives in gas and solid phases

Combustion Bomb Study (high $p$ and $T$ ) Design and construction of facility

Set up optical diagnostics

Study of ignition and combustion of suspensions of coal and char

Feasibility Study of Alt. Systems. e.g., 1. Very high pressure and temp. adiabatic compression system.

2. Scaled pulverized coalfired system

Fiscal Year

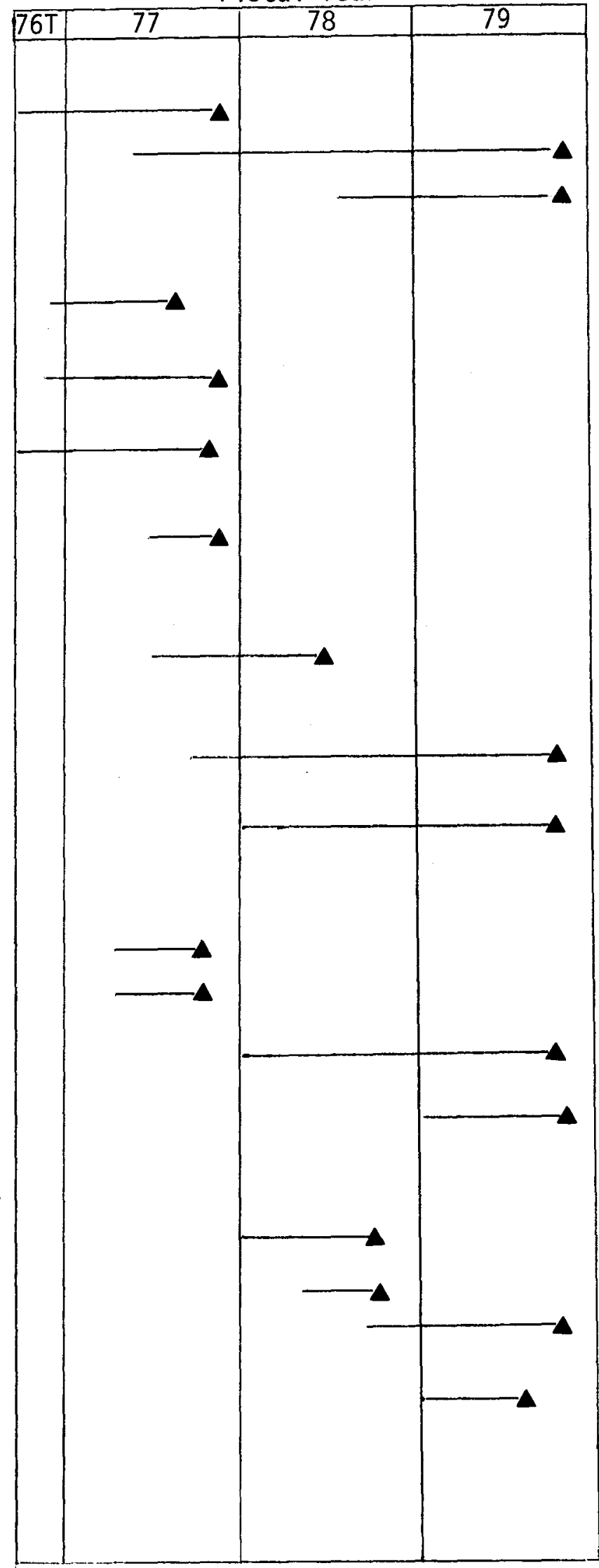




\section{REFERENCES}

1. G. R. Hill and D. P. Teixeira, "Combustion Research and The Electric Power Research Institute," Keynote Address, Spring Meeting of the Western States Section of the Combustion Institute, Salt Lake City, April 1976.

2. A. B. Walker, "Comments on the State-of-the-Art for Control of Particulate Emissions from Power Plant Stacks," in Power Plants and Clean Air; the State- ofthe-Art, Winter Meeting of Power Engineering Society, New York, January 1973.

3. Professor R. F. Sawyer, U. C. Berkeley, formerly member of the California State Air Resources Board, private communication.

4. W. W. Habelt and A. P. Selker, "Operating Procedures and Prediction for $\mathrm{NO}_{\mathrm{x}}$ Control in Steam Power Plants," paper presented at Central States Meeting of the Combustion Institute, Madison, March 1974.

5. A. R. Crawford, E. H. Manny, M. W. Gregory and W. Bartok, "The Effect of Combustion Modification on Pollutants and Equipment Performance of Power Generation Equipment," paper presented at Symposium on Stationary Source Combustion, sponsored by U.S.E.P.A., Atlanta, September 1975.

6. "Reduce Nitrogen-0xides Emissians," Power, September 1972.

7. A. T. Yu, "Lower Cost Energy and Higher Quality Coke Through Coal Blending," Coal Age, 112, 1975.

8. W. Bartok, Control of Nitrogen Oxide Emissions from Power Plant Boilers," in Power Plants and Clean Air; the State-of-the-Art, Winter Meeting of Power Engineering Society, New York, January 1973.

9. C. McCann, J. Demeter, R. Snedden and D. Bienstock, "Combustion Control of Pollutants from Multi-Burner Coal-Fired Systems," EPA Report No. 650/2-74-038, May 1974. 
10. I. Glassman and W. A. Sirignano, "Summary Report of the Workshop on Energy-Related Basic Combustion Research," sponsored by NSF, Princeton University, Department of Aerospace and Mechanical Sciences, Report No. $1177,1974$.

11. D. L. Hartley, D. R. Hardesty, M. Lapp, J. Dooher and F. Dryer, "The Role of Physics in Combustion," in the Efficient Use of Energy, AIP Conference Proceedings, No. 25, American Institute of Physics, New York, 1975.

12. J. B. Heywood, "Combustion Modeling in Automotive Engines," Physics and the Energy Problem - 1974, AIP Conference Proceedings, No. 19, edited by M. D. Fiske and W. W. Havens, Jr., American Institute of Physics, New York, 1974.

13. B. C. Krippene, "Burner and Boiler Alterations for $\mathrm{NO}_{X}$ Control," paper presented at Central States Combustion Section Meeting, Madison, March 1974.

14. D. W. van Krevelen, Coal Science, Elsevier, Amsterdam, 1961 .

15. H. H. Lowry, editor, Chemistry of Coal Utilization, Wiley and Sons, New York, 1963.

16. M. A. Field, D. W. Gil1, B. B. Morgan and P. G. W. Hawksley, Combustion of Pulverised Coal, British Coal Utilisation Research Association (BCURA), Leatherhead, 1967.

17. M. F. R. Mulcahy and I. W. Smith, "Kinetics of Combustion of Pulverized Fuel: A Review of Theory and Experiment," Rev. Pure and Appl. Chem. 19, 1969, p. 81 .

18. D. Gray, J. G. Cogoli and R. H. Essenhigh, "Problems in Pulverized Coal and Char Combustion;" in Coal Gasification, Advances in Chemistry Series 131, American Chemical Society, Washington, 1974.

19. D. G. Skinner, The Fluidized Combustion of Coal, National Coal Board, Research and Development Department, London, 1970.

20. J. B. Heywood and G. J. Womack, Open Cycle MHD Power Generation (Chapter 4: Combustion), Pergamon Press, London, 1969.

21. BCURA Annual Reports, British Coal Utilisation Research Association, Leatherhead, 1960-1968.

22. M. A. Field, "Rate of Combustion of Size-Graded Fractions of Char from a Low-Rank Coal Between $1200^{\circ}$ and $2000^{\circ} \mathrm{K}$, Combustion and Flame 13, 1969, p. 237. 
23. S. Badzoich and P. G. W. Hawksley, "Kinetics of Thermal Decomposition of Pulverized Coal Particles," Ind. Eng. Chem Process Dev. 9, 1970, p. 521 .

24. D. Anson, F. D. Moles and P. J. Street, "Structure and Surface Area of Pulverized Coal During Combustion," Comb. and Flame 16, $1971, \mathrm{p} .265$.

25. M. M. Baum and P. J. Street, "Predicting the Combustion Behavior of Coal Particles," Combustion Science and Technology 3,1971, p. 231 .

26. A. R. Ramsden and I. W. Smith, "Further Evidence For Internal Burning In Particles of Pulverized Coal, "Fuel: Lond. 47,1968, p. 253 .

27. I. W. Smith, "Kinetics of Combustion of Size-Graded Pulverized Fuels in the Temperature Range 1200 - $2270^{\circ} \mathrm{K}$," Comb: and Flame 17, 1971, p. 303.

28. I. W. Smith, "The Kinetics of Combustion of Pulverized Semi-Anthracite in the Temperature Range $1400-2200^{\circ} \mathrm{K}$," Comb. and Flame 17, 1971, p. 421.

29. A. B. Ayling and I. W. Smith, "Measured Temperatures of Burning Pulverized-Fuel Particles, and the Nature of the Primary Reaction Product," Comb. and Flame 18, 1972 , p. 173 .

30. R. J. Hamor, I. W. Smith and R. J. Tyler, "Kinetics of Combustion of a Pulverized Brown Coal Char Between 630 and 22000K," Comb. and Flame 21, 1973, p. 153.

31. I. W. Smith and R. J. Tyler, "The Reactivity of Porous Brown Coal Char to Oxygen between 630 and $18120 \mathrm{~K}$," Comb. Sci. and Tech 9,1974, p. 87.

32. J. B. Howard and R. H. Essenhigh, "Pyrolysis of Coal Particles in Pulverized Fuel Flames," Ind. and Engr. Chem. Process Des. and Dev. 6, January 1967, p. 74.

33. J. B. Howard and R. H. Essenhigh, "Mechanism of SolidParticle Combustion With Simultaneous Gas-Phase Volatiles Combustion," Eleventh Symposium (International) on Combustion, Combustion Institute, Pittsburgh, 1967, p. 399.

34. L. D. Smoot, M. D. Horton and G. Williams, "Propagation of Laminar Pulverized Coal-Air Flames," paper presented at Spring Meeting of Western States Section/The Combustion Institute, Salt Lake City, Apri1, 1976. 
35. T. A. Milne and J. E. Beachey, "Laboratory Studies of the Combustion, Inhibition and Quenching of Coal Dust-Air Mixtures," paper presented at Spring Meeting of Western States Section/The Combustion Institute, Salt Lake City, April 1976 .

36. M. A. Nettleton and R. Stirling, "The Ignition of Clouds of Particles in Shock-Heated Oxygen," Proc. Roy. Soc. 300, 1967, p. 62 .

37. M. A. Nettleton and R. Stirling, "The Combustion of Clouds of Coal Particles in Shock-Heated Mixtures of 0xygen and Nitrogen," Proc. Roy. Soc. 322, 1971, p. 207.

38. M. A. Nettleton and R. Stirling, "The Influence of Additives On the Burning of Clouds of Coal Particles in Shocked Gases," Comb. and Flame 22, 1974. p. 407.

39. D. B. Anthony, J. B. Howard, H. C. Hottel and H. P. Meissner, "Rapid Devolatilization of Pulverized Coal," Fifteenth Symposium (Internationa 1) on Combustion, The Combustion Institute, Pittsburgh, 1974, p. 1303.

40. D. Bienstock, R. C. Kurtzrode, R. J. Denski and J. H. Field, "Experimental Unit for Study of High-Temperature Combustion of Coal for MHD Power Generation," ASME Paper No. 62-WA-147, 1962 .

41. D. Bienstock, J. J. Lacey, P. D. Bergman, R. J. Denski and J. M. Henry, "Coal Combustion Aspects of MHD Power Generation," in Proc. of First US-USSR Colloquium on MHD Power Generation, February 1974 .

42. J. B. Dicks, L. W. Crawford, J. W. Muehlhauser, J. F. Martin, N. L. Loeffler and B. S. Arora, "The Direct-Coal-Fired MHD Generator System," Fourteenth Symposium on Engineering Aspects of MHD, II.T.T, April 1974 .

43. R. H. Essenhigh, Review of Reference 17, Fire Research Abstracts and Reviews 13, 1971, p. 68 .

44. G. L. Fisher, D. P. Y. Chang and M. Brummer, "Fly Ash Collected from Electrostatic Precipitators: Microcrystalline Structures and the Mystery of the Spheres," Science 192, May 1976, p. 553.

45. F. A. Bagwe11, K. E. Rosentha1, D. P. Teixeira, B. P. Breen, N. B. de Volo and S. Kerho, "Utility Boiler operating Modes for Reduced Nitric Oxide Emissions," J. Air Poll. Control Assoc. 21, November 1971, p. 702 . 
46. P. H. Given, Fuel 39, 1960, p. 147

47. P. B. Hirsch, Proc. Roy. Soc. A226, 1954, p. 143.

48. An Analysis of the ERDA PIan and Program, Office of Technology Assessment, United States Congress, Section 9. Direct Coal Utilization, October 1975.

49. R. E. Mitchell, "Nitrogen Oxide Formation from ChemicallyBound Nitrogen During the Combustion of Fossil Fuels," Sandia Laboratories, Livermore, Report SAND76-8227, June 1976. 


\section{UNLIMITED RELEASE}

\section{INITIAL DISTRIBUTION}

U. S. Energy Research and Development Administration

Washington, D. C. 20545

Attn: Dr. E. Karl Bastress, Chief, Combustion Technology Branch, Division of Conservation Research and Technology

Dr. John A. Belding, Director, Division of Conservation Research and Technology

Dr. Jorgen W. Birkeland, Division of Conservation Research and Technology

Jerry Hudis, Chemical and Atomics Physics Branch, Division of Physical Research

Dr. James S. Kane, Deputy Assistant Administrator for Physical Research, Solar Geothermal and Advanced Energy Systems

Andrej Macek, Chief, Combustion and Power Branch, Fossi 1 Energy Richard V. Shanklin, MHD-Fossil Energy

Marshall Sluyter, MHD-Fossil Energy

G. A. Samara, 5130

L. W. Davison, 5131

M. Cowan, 5230

W. B. Leisher, 5233

K. J. Touryan, 5260

R. A. Hill, 5262

H. M. Stoller, 5730

M. Lieberman, 5731

D. A. Northrup, 5732

T. B. Cook, Jr., 8000, Attn: C. H. DeSe1m, 8200, and W. C. Scrivner, 8400

L. Gutierrez, 8100, Attn: W. E. Alzheimer, 8120, D. E. Gregson, 8150,

A. N. B1ackwe 11, 8110

R. D. Cozine, 8160 , and C. S. Selvage, 8180

D. R. Hardesty, 8115 (15)

D. L. Hartley, 8115 (2)

R. E. Mitche11, 8115

C. W. Robinson, 8116

B. F. Murphey, 8300

Technical Publications and Art Division, 8265, for TIC (2)

F. J. Cupps, 8265/Classification and Technical Library Processing Division, 3141 Classification and Technical Library Processing Division, 3141 (4)

Library and Security Classification Division, 8266-2 (5)

$\mathrm{DRH}: 8115: \mathrm{sb}$ 